Polymer Journal, Vol. 6, No. 1, pp 45-50 (1974)

\title{
Strain Dependence of Glass Transition Point in Chlorinated Polyethylene Vulcanizate
}

\author{
Motosuke NAOKI and Takuhei NosE \\ Department of Polymer Technology, Tokyo Institute of Technology, \\ Ookayama, Meguro-ku, Tokyo, Japan.
}

(Received June 16, 1973)

\begin{abstract}
The static tensile force and the velocity of sound were measured simultaneously in vulcanized chlorinated polyethylene at temperatures ranging from $-20^{\circ} \mathrm{C}$ to $30^{\circ} \mathrm{C}$. The starting point of the thermal shrinking in variously elongated samples were also measured. The apparent glass transition temperature increases with the increase of the extension ratio in the sound velocity measurement and the thermal shrinkage, while the apparent glass transition temperature decreases in the tensile force measurement. These facts indicate that the extension dependence of the apparent glass transition temperature changes with the physical quantities observed.

KEY WORDS Strain / Glass Transition / Chlorinated Polyethylene /

Sound Velocity / Thermal Shrinkage /
\end{abstract}

Many arguments have been presented about the glass transition phenomena, e.g., it occurs at the point in the conditions of the isoviscosity, ${ }^{1}$ the isofree-volume ${ }^{2}$ or the isoconfigurationalentropy or enthalpy. ${ }^{3}$ In these arguments the glass transition point is considered as the freezing point of the segmental motion and one of the direct reflections of the molecular mobility. On the other hand the apparent glass transition point obtained experimentally is the inflection point of a certain physical quantity from liquid to glassy state. The temperature of this inflection point associated with the glass transition is here called the apparent glass transition temperature $T_{\mathrm{g}}{ }^{\text {app }}$. Therefore it gives rise a problem of whether the molecular mobility is reflected by the inflection points of all physical quantities directly or not. In the present case the problem is whether the strain dependence of a certain physical quantity corresponds to the dependence of the molecular mobility on extension.

The first study of the extension dependence of the glass transition point was made by $R$. S. Witte and R. L. Anthony for some typical rubbers by the method of the tensile force. ${ }^{4}$ They concluded that the glass transition temperature in extension decreased with the increase of elongational ratio in butyl rubber. On the contrary it was reported by G. Gee, P. N.
Hartley, J. B. M. Herbert and H. A. Lanceley, ${ }^{5}$ and A. Komatsu and T. Nose ${ }^{6}$ that the glass transition point in dilatometric measurements rose a little with elongation for some crosslinked polymers. The main problem in comparing those results is that the samples, the methods of measurements and the conditions of the glass forming are all different in each experiment. In order to clear this apparent discrepancy it is necessary for the same sample to be measured under the same conditions. If two methods are available for simultaneous use and have no interactions with each other, they will be suitable for this purpose. In this paper we present a way of combining the two methods, i.e., the tensile force and the propagation of sound, which can be measured at the same time. The static tensile force was not affected by the vibrational stimulation in the accuracy of our experiment.

The measurement of the sound velocity in some extended rubbers was formerly reported by P. Mason, ${ }^{7}$ but those rubbers used had so low glass transition temperatures that the dependence of those temperatures on extension was not measured clearly. As the sample studied here, i.e., the unstretched chlorinated polyethylene, changes into glassy state at comparatively high temperature, i.e., $-12.1^{\circ} \mathrm{C}$ in dilatometry, that 
dependence can be easily observed.

For some unvulcanized polymers, it was reported that the starting temperature of thermal shrinking decreased with the elongational ratio for frozen amorphous polymers extended in the liquid state. ${ }^{8}$ To compare with those results, the thermal shrinkage was also measured for the specimen studied.

\section{EXPERIMENTAL}

\section{Material}

The chlorinated polyethylene sample used for the present study is a commercial product of Showa-denko Company, and the synthetic method and the characteristic of this sample are shown in ref 9. The vulcanization of chlorinated polyethylene which contained chlorine $39.1 \mathrm{wt} \%$ was carried out using zinc oxide at $150^{\circ} \mathrm{C}$. The test specimen was purified by repeating the swelling and extracting procedures in tetrahydrofuran and methyl alcohol respectively. After drying completely in a vacuum at $80^{\circ} \mathrm{C}$, the specimen was relaxed at $80^{\circ} \mathrm{C}$ for three days at an extension ratio of about 2 .

The Static Tensile Force and the Sound Velocity

Figure 1 shows the equipment to measure the tensile force and the sound velocity. It consists of two sections. The upper part is the air bath maintained at $28^{\circ} \mathrm{C}$ to avoid the thermal drift of the strain gauge. The test specimen, the pickup crystals and the magnetic generator of sound waves are in the chamber at the lower part, which can be controlled at various temperatures within $\pm 0.02^{\circ} \mathrm{C}$ by circulating water or methanol through the outer side from the controlled bath. The chamber was filled by dried nitrogen gas to avoid the dispersion in sound velocity caused by water and to prevent the specimen from oxidative degradation.

As the distance of the two pickup crystals could not be measured through the glass window because of frost, the changes of frequency about $1 \mathrm{kHz}-4 \mathrm{kHz}$ were measured keeping the phase difference and the distance constant between the two pickups. The test specimen was about 10 $\mathrm{cm}$ in length and $0.0045 \mathrm{~cm}^{2}$ in cross-sectional area in the unstretched state. The measurement was performed by cooling at the rate of -0.25 ${ }^{\circ} \mathrm{C} / \mathrm{min}$ and $-0.15^{\circ} \mathrm{C} / \mathrm{min}$.

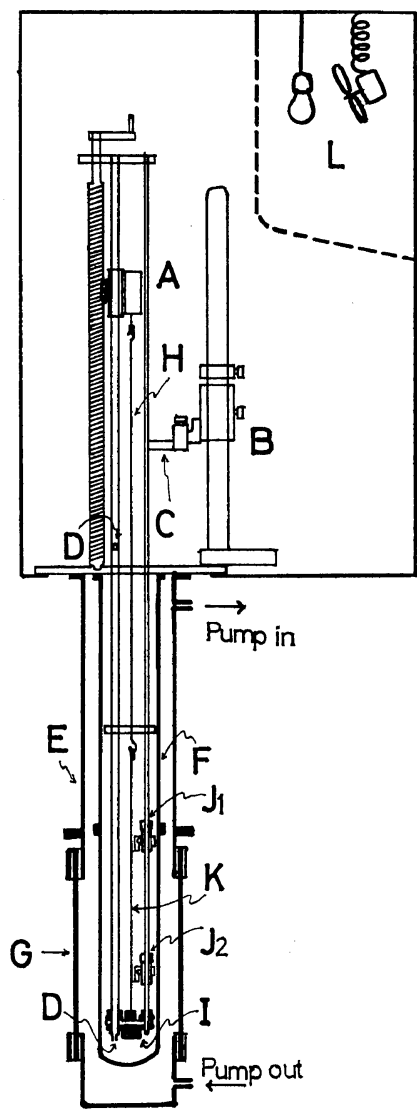

Figure 1. Apparatus for the measurements of tensile force and sound velocity: A) strain gauge; B) micrometer of pickup crystals; C) pickup holder; D) leading tube of $\mathrm{N}_{2}$ gas; E) brass tube for circulating liquid; F) glass chamber; G) glass window; H) hock; I) generator of sound wave; $\mathbf{J}_{1}, \mathbf{J}_{2}$ ) pickups; K) sample; L) heater and fun.

\section{The Thermal Shrinkage of the Stretched Glassy Specimen}

The specimen stretched at room temperature with a fixed length was thrown into the methanol bath controlled at $-40^{\circ} \mathrm{C}$. Then, after cutting off its clamp, the change in the length of the specimen was measured on heating at the rate of $0.3^{\circ} \mathrm{C} / \mathrm{min}$.

\section{The Dilatometry and the Differential Scanning Calorimeter}

For the unstretched specimen the glass transition temperature was measured by the dilatometer on cooling at the rate of $-0.3^{\circ} \mathrm{C} / \mathrm{min}$. The DSC measurement was also made at the scanning speed 
of $16^{\circ} \mathrm{C} / \mathrm{min}$ for the unstretched glassy specimen formed by cooling at the rate of $-16^{\circ} \mathrm{C} / \mathrm{min}$ from liquid state.

\section{RESULTS}

In the unstretched state the glass transition temperature was $-12.1^{\circ} \mathrm{C}$ and $-10.9^{\circ} \mathrm{C}$ by the dilatometric and DSC measurements respectively. The initial inflection point of the DSC curve was taken as the glass transition temperature. The glass transition temperature of the specimen studied was higher than that of the unvulcanized chlorinated polyethylene by about $15^{\circ} \mathrm{C}$.

The static tensile force as a function of temperature is indicated in Figure 2. The inversion

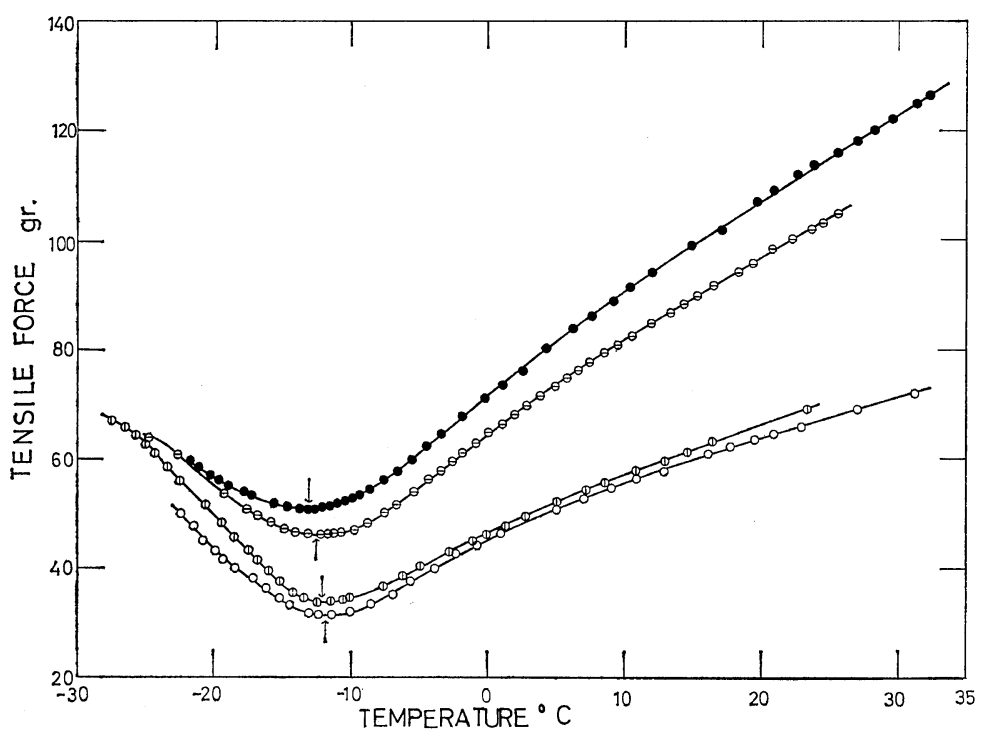

Figure 2. Variation of the tensile force with temperature at constant length. Arrows indicate the inversion points of the tensile force. The extension ratios are: $\bigcirc, 1.572$; (1) $1.583 ; \ominus, 2.061 ; \bullet, 2.447$ at $25^{\circ} \mathrm{C}$.

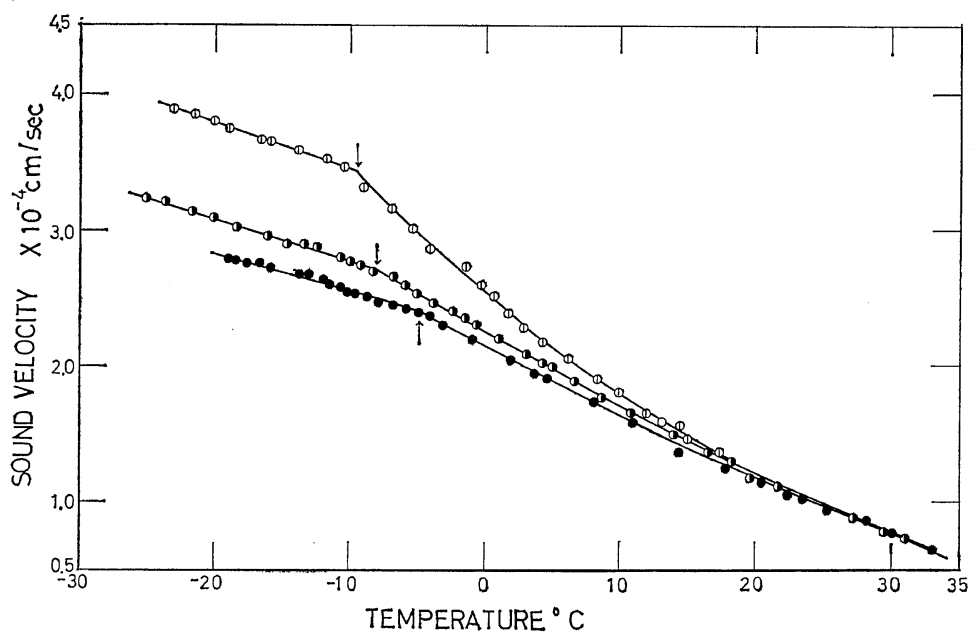

Figure 3. Variation of the sound velocity with temperature at constant length. Arrows indicate the apparent glass transition points. The extension ratios are: (1), 1.583; $\bigcirc$, $2.274 ; 0,2.447$ at $25^{\circ} \mathrm{C}$. 
Table I. $T_{\mathrm{g}}$ app in chlorinated polyethylene vulcanizate studied at various fixed lengths

\begin{tabular}{clll}
\hline & \multicolumn{3}{c}{ Method } \\
\cline { 2 - 3 } $\begin{array}{c}\text { Extension } \\
\text { ratio at } \\
25^{\circ} \mathrm{C}\end{array}$ & $\begin{array}{c}\text { Tensile force } \\
\text { Inversion } \\
\text { point }\end{array}$ & $\begin{array}{c}\text { Extrapo- } \\
\text { lation }\end{array}$ & $\begin{array}{c}\text { Sound } \\
\text { velocity }\end{array}$ \\
\hline $1.572^{\mathrm{a}}$ & $-11.9^{\mathrm{a}}{ }^{\circ} \mathrm{C}$ & $-11.6^{\mathrm{a}}{ }^{\circ} \mathrm{C}$ & $-9.2^{\mathrm{a}}{ }^{\circ} \mathrm{C}$ \\
1.583 & -12.1 & -12.6 & -9.6 \\
2.061 & -12.6 & -12.6 & -8.4 \\
2.247 & - & -12.4 & -7.5 \\
2.447 & -13.2 & -12.5 & -4.8 \\
\hline
\end{tabular}

a Under the different glass forming condition comparing with others as indicated in the text.

points of the static force were observable directly by the inversion points of the resistance balance meter. These inversion points are indicated as arrows in Figure 2 and numerically in Table $I$. The points of intersections of extrapolations from liquid and glassy regions are also indicated in Table I, but no clear dependence on extension could be observed. The cooling rate was 0.25 ${ }^{\circ} \mathrm{C} / \mathrm{min}$ for the specimen at extension ratios of $1.583,2.061,2.247$ and 2.447 , while it was 0.15 ${ }^{\circ} \mathrm{C} / \mathrm{min}$ for the specimen at the ratio of 1.572 .

The sound velocity is indicated in Figure 3. The sound velocity for different extension ratios almost agreed with each other in the liquid region, but on the contrary the velocity changed remarkably in the glassy region, i.e., the velocity decreased with elongation. $T_{\mathrm{g}}$ app on sound velocity were decided by the intersections of lines drawn from glassy and liquid regions. Those numerical results are shown in Table $I$.

Some results of the measurement on shrinking are indicated in Figure 4. The specimen shrank slowly at the beginning, but at a certain point the shrinking speed increased suddenly. The strain dependence of that point were treated as the strain dependence of $T_{\mathrm{g}}^{\text {app }}$ in the thermal

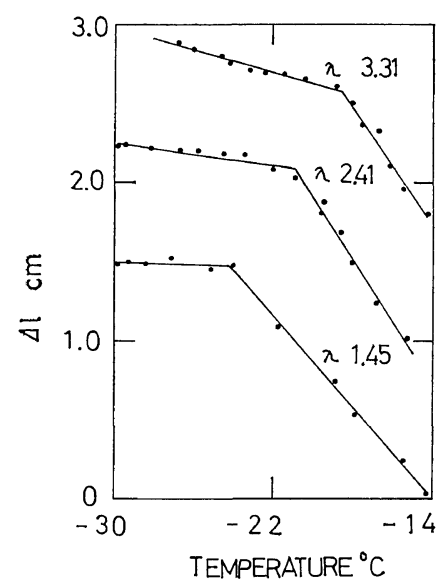

Figure 4. Some examples of the thermal shrinkage with temperature. Axis of ordinate is choosed for an arbitrary basic point. The approximate elongations at $25^{\circ} \mathrm{C}$ are indicated.

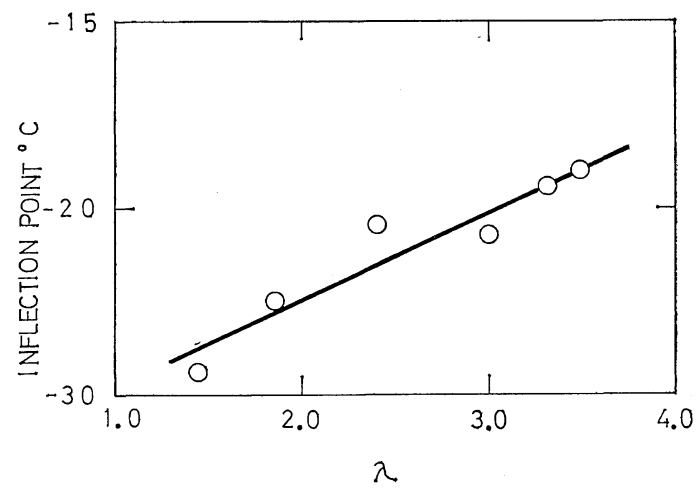

Figure 5. Variation of inflection points on shrinking with elongation at $25^{\circ} \mathrm{C}$.

Table II. The magnitude of the strain dependence of $T_{\mathrm{g}}$ app

\begin{tabular}{ccccccc}
\hline \multirow{2}{*}{ Method } & \multicolumn{2}{c}{ Tensile force } & & Sound \\
\cline { 2 - 4 } & $\begin{array}{c}\text { Inversion } \\
\text { point }\end{array}$ & $\begin{array}{c}\text { Extrapo- } \\
\text { lation }\end{array}$ & $\begin{array}{c}\text { Thermal } \\
\text { shrinkage }\end{array}$ & Dielectricity & Dilatometry \\
\hline$\frac{\mathrm{d} T_{\mathrm{g}}{ }^{\mathrm{app}}}{\mathrm{d} \lambda},{ }^{\circ} \mathrm{C}$ & -1.2 & 0 & $\begin{array}{l}1.4(\lambda=1.5) \\
4.6(\lambda=2.2)\end{array}$ & 2.5 & $2.0^{\mathrm{a}}$ & $\begin{array}{l}1.2(\lambda=1.5)^{\mathrm{b}} \\
1.8(\lambda=1.7)^{\mathrm{c}}\end{array}$ \\
\hline
\end{tabular}

a By M. Naoki, K. Nakajima, T. Nose, and T. Hata for vulcanized chlorinated polyethylene. ${ }^{9}$

b By A. Komatsu and T. Nose for vulcanized styrene-butadiene copolymer. ${ }^{6}$

c By G. Gee, P. N. Hartley, J. B. M. Herbert, and H. A. Lanceley for natural rubber. ${ }^{5}$ 
Table III. $T_{\mathrm{g}}$ app in unstretched chlorinated polyethylene vulcanizate

\begin{tabular}{|c|c|c|c|c|c|c|}
\hline \multirow[b]{2}{*}{ Method } & \multirow[b]{2}{*}{ DSC } & \multirow[b]{2}{*}{ Dilatometry } & \multicolumn{2}{|c|}{ Tensile force } & \multirow{2}{*}{$\begin{array}{c}\text { Sound } \\
\text { velocity }\end{array}$} & \multirow{2}{*}{$\begin{array}{l}\text { Thermal } \\
\text { shrinkage }\end{array}$} \\
\hline & & & $\begin{array}{c}\text { Inversion } \\
\text { point }\end{array}$ & $\begin{array}{c}\text { Extrapo- } \\
\text { lation }\end{array}$ & & \\
\hline $\mathrm{T}_{\mathrm{g}}^{\mathrm{app},{ }^{\circ} \mathrm{C}}$ & -10.9 & -12.1 & -11.4 & -12.6 & -10.0 & -25 \\
\hline $\begin{array}{l}\text { Glass forming } \\
\text { condition, } \\
{ }^{\circ} \mathrm{C} / \mathrm{min}\end{array}$ & $-16.0^{a}$ & -0.3 & -0.25 & -0.25 & -0.25 & quench $^{\mathrm{b}}$ \\
\hline
\end{tabular}

$\mathrm{a}, \mathrm{b}$ These were measured under heating rates of $16.0^{\circ} \mathrm{C} / \mathrm{min}$ and $0.3^{\circ} \mathrm{C} / \mathrm{min}$ respectively.

shrinkage. Those inflection points are plotted with extension ratio in Figure 5. It seems that the shrinking temperature increases linearly with the extension ratio.

Table II shows the results of the magnitude of the dependence of $T_{\mathrm{g}}$ app on extension by various measurements.

As the specimen bent noticeably in the lower extension ratios because of the weights of the pickup crystals, the data on the sound velocity in the lower elongational region was not available. Therefore $T_{\mathrm{g}}{ }^{\mathrm{app}}$ of the static force and sound velocity for the unstretched state were evaluated by extrapolating the extension ratios unity. These results are indicated in Table III.

\section{DISCUSSION}

The effect of the cooling rate in $T_{\mathrm{g}}$ app were found as shown in Table $I$. The difference in $T_{\mathrm{g}}$ app between the extension ratios of 1.572 and 1.583 may be mainly due to the difference in cooling rate. In the extrapolation method the effect of the cooling rate is larger that by the other methods. Formerly Witte, et al., also reported that the time effect affected the apparent glass transition points significantly in the extrapolation method. ${ }^{4}$ This fact shows that the inversion point method is better at least in experiment than the extrapolation method where the extrapolation point is considerably influenced by the tensile force curve in the glassy region.

The dependence of $T_{\mathrm{g}}$ app on extension in the two methods, i.e., the tensile force and the sound velocity, were opposite in sign in the simultaneous measurements. This fact shows that the inflection points associated with the glass transition in all the physical quantities do not necessarily reflect the molecular mobility directly. The experimental results of the physical quantities reflecting the molecular mobility need to be compared with the arguments, e.g., isofree-volume or isoconfigurational-entropy. For such a rational comparison, the problem of interpreting the behavior of the physical properties in the vicinity of the glass transition temperature should be solved first.

The apparent glass transition temperatures observed by the thermal shrinkage were lower than those by the other methods, but the magnitude of the dependence of those points on extension was not very different from those of other measurements. The lower glass transition points are considered to be caused by swelling due to the methanol. Methanol is so poor a solvent for chlorinated polyethylene that no particular change was recognized in appearance, but even if a small amount of low molecular solvent penetrates into the sample, the mobility of the segmental motion will be influenced significantly.

The dependence of the shrinking points on extension has the opposite tendency to those of unvulcanized polymers. ${ }^{8}$ It is commonly said in such a case that the species in the glassy state have a frozen-in internal stress and it thaws at the glass transition point. Therefore, regardless of the vulcanization, the increase of the frozenin stress may advance its thawing. From this point of view our results are contradictory. To explain this phenomenon it seems that the decrease of the configurational entropy lowers the mobility of the segments in the glass transition region for the vulcanized species, whereas such a effect is smaller in the unvulcanized ones because some of the decreased configurational entropy under extension recovers due to the relaxation with the flow of the molecules. This 
opinion conforms to the argument that the glass transition point is decided by the configurational condition, ${ }^{3}$ but the opposite property of $T_{\mathrm{g}}{ }^{\mathrm{app}}$ in tensile force is inexplicable by that.

As shown in Figure 3 the sound velocity in the glassy state decreased with increasing elongational ratio, and in the liquid state, however, the dependence of the velocity on extension decreased with increasing temperature. The density, i.e., the distance between atoms, can be considered as the major factor which decides the sound velocity in the glassy state. Generally the crosslinked material increases its volume with elongation in the liquid and freezes when it is in the glassy state. ${ }^{6}$ This may be the reason why the sound velocity decreases with the increase in the elongational ratio. In the liquid state, however, the scattering effect caused from the molecular motion also plays an important role in the propagation of the sound, and any differences in the density have little importance at higher temperature.

In the experiment of the sound velocity as indicated in Figure 3, it seems that the increase of the extension makes the higher $T_{\mathrm{g}}{ }^{\mathrm{app}}$ and, in the extreme, the apparent glass transition point will disappear. This phenomenon suggests that the situation of the molecular motion along the extension direction in the liquid state becomes more similar to that in the glassy state with the increase in elongation. More detailed consideration of the molecular mobility needs information on the molecular motion perpendicular to the extension directions, and the particular properties of the mobility by dielectricity ${ }^{10}$ under extension will be discussed in the succeeding paper.

It was observed that $T_{\mathrm{g}}$ app for the unstretched specimen changed with the variation of the methods as indicated in Table III. Two of the reasons of this phenomenon are considered to be the usually accepted ones of the effect of the glass forming conditions and the time scale of measurements, but another significant factor has to be considered, i.e., that the apparent glass transition temperature depends on the kind of the variables which we observe, e.g., volume, enthalpy, tensile force or each modulus.

\section{CONCLUSION}

The experimental glass transition temperature observed as the inflection point in a certain physical quantity, i.e., $T_{\mathrm{g}}$ app, changes not only with glass forming conditions but also with the variables observed. Moreover the change of $T_{\mathrm{g}}$ app with extension largely depends on the observed variables. These results indicate that $T_{\mathrm{g}}$ app in a certain physical quantity is not necessarily the direct reflection of the molecular mobility.

Acknowledgments. We have received considerable help and advice from Professor Toshio Hata. Particular acknowledgments are due to Dr. T. Saito at the Research Laboratories of Showadenko Company who prepared the sample studied, and to Dr. K. Yamamoto at the Research Laboratories of Japan Synthetic Rubber Company who carried out the vulcanization of this sample, and to Mr. T. Minato, Mr. K. Miyasa$\mathrm{ka}$ and Mr. M. Motomura for their considerable assistance in measurement.

\section{REFERENCES}

1. R. F. Boyer and R. S. Spencer, J. Appl. Phys., 16, 594 (1945).

2. T. J. Fox and P. J. Flory, ibid., 21, 581 (1950); J. D. Ferry, "Viscoelastic Properties of Polymers," John Wiley \& Sons, Inc., New York, N. Y., 1961, p 218.

3. M. Goldstein, J. Chem. Phys., 39, 3369 (1963); G. Adam and J. H. Gibbs, ibid., 43, 139 (1965); T. Nose, Polymer J., 2, 445 (1971); ibid., 4, 217 (1973).

4. R. S. Witte and R. L. Anthony, J. Appl. Phys., 22, 689 (1951).

5. G. Gee, P. N. Hartley, J. B. M. Herbert, and H. A. Lanceley, Polymer, 1, 365 (1960).

6. A. Komatsu and T. Nose, Rep. Progr. Polym. Phys. Japan, 14, 309 (1971).

7. P. Mason, J. Appl. Polym. Sci., 1, 63 (1959); P. Mason, Soc. Chem. Inds., Monograph No. 5 (London), 1461 (1959).

8. F. H. Müller, Kolloid Zh., 95, 138 (1941); J. Stölting and F. H. Müller, Kolloid Zh. Z. Polym., 238, 459 (1970).

9. T. Saito, Y. Matsumura, and S. Hayashi, Polymer J., 1, 639 (1970); T. Saito, K. Yamaguchi, and S. Hayashi, Kobunshi Kagaku (Chem. High Polymers), 29, 78 (1972).

10. M. Naoki, K. Nakajima, T. Nose, and T. Hata, to be published. 